\title{
SUSCEPTIBILIDADE ÀS CHEIAS NA ÁREA METROPOLITANA DE LISBOA NORTE \\ FACTORES DE PREDISPOSIÇÃO E IMPACTES \\ DAS MUDANÇAS DE USO DO SOLO
}

Miguel LeAL ${ }^{1}$

CATARINA RAMOS ${ }^{2}$

\begin{abstract}
Resumo - Neste trabalho foram analisadas e comparadas doze bacias hidrográficas do sector norte da Área Metropolitana de Lisboa (AML), com um histórico de cheias que têm provocado, recorrentemente, vítimas mortais e outras consequências danosas. A metodologia de análise baseou-se no cálculo de indicadores quantitativos referentes aos factores de predisposição (naturais) às cheias (geometria das bacias, substrato geológico, relevo e rede de drenagem) e a factores antrópicos (neste caso, uso do solo e sua evolução), a partir dos quais foram desenvolvidos índices de susceptibilidade às cheias, através da utilização de Sistemas de Informação Geográfica. Os resultados deste estudo permitiram detectar: (i) as bacias de maior susceptibilidade às cheias; (ii) os factores condicionantes para a formação de cheias em cada uma das bacias; (iii) os impactes das modificações do uso do solo nos tempos de concentração e nos caudais de ponta, que aumentam a velocidade de progressão e magnitude das cheias, potenciando a sua perigosidade; (iv) o aumento generalizado da construção nas Zonas Afectadas por Cheias (ZAC), que incrementa a exposição e o risco de cheia na AML.
\end{abstract}

Palavras-chave: Cheias, susceptibilidade, factores condicionantes, AML, bacias hidrográficas, ZAC.

Abstract - SUSCEPTIBILITY TO FLOODING IN NORTHERN Lisbon METROPOLITAN AREA. NATURAL FACTORS AND IMPACTS OF CHANGES IN LAND USE. Twelve drainage basins in the Northern Lisbon Metropolitan Area (LMA) were analysed and compared because they are affected by floods that threaten life and livelihoods. The methodology was based on the calculation of quantitative indicators that reflect natural and human factors of floods (basin geometry, geological substrate, relief and drainage network in the $1^{\text {st }}$ case; land use

Recebido: Maio 2012. Aceite: Fevereiro 2013.

1 Investigador do CEG-IGOT-UL, núcleo SLIF - Sistemas Litorais e Fluviais: Dinâmicas, Mudanças Ambientais e Ordenamento do Território. E-mail: miguelleal11@hotmail.com.

2 Professora Associada do IGOT-UL; Investigadora do CEG-IGOT-UL, núcleo SLIF. E-mail: catramos@campus.ul.pt. 
classes and land usage changes in the $2^{\text {nd }}$ case). Susceptibility indexes to flooding were developed based on these indicators, using Geographical Information Systems. The results of this study led to the identification of: (i) the basins with highest susceptibility to flooding; (ii) the conditioning factors that mostly contribute to the formation of floods in each basin; (iii) the impacts of changes in land use on the concentration times and peak discharges, which increase the flood hazard; (iv) the urban growth in the flood-prone zones, which increases exposure and the flood risk in the LMA.

Keywords: Floods, susceptibility, conditioning factors, Lisbon Metropolitan Area, drainage basins, flood-prone zone.

Résumé - SUSCEPTIBILITÉ AUX CRUES DANS LA ZONE MÉTROPOLITAINE NORD DE LISBONNE. FACTEURS DE PRÉDISPOSITION ET IMPACTS DES CHANGEMENTS D'UTILISATION DU SOL. Cette étude a analysé et comparé douze bassins versants de la partie nord de la zone métropolitaine de Lisbonne (ZML), où des inondations ont provoqué, de façon récurrente, de nombreux décès et autres conséquences néfastes. L'analyse a été basée sur le calcul d'indicateurs quantitatifs des facteurs naturels des crues (géométrie des bassins, substrat géologique, relief et réseau hydrographique) et des facteurs anthropiques (utilisation du sol et son évolution). Ces indicateurs ont permis, à l'aide de systèmes d'information géographique, la définition d'indices de susceptibilité aux crues. On a aussi détecté: (i) les bassins de plus grande susceptibilité aux crues; (ii) les facteurs conditionnant les crues dans chacun des bassins versants; (iii) l'impact des changements d'utilisation du sol sur les durées de concentration et sur les débits de crue, ce qui augmente leur vitesse de progression et leur magnitude; (iv) une croissance générale de la construction dans les zones inondables, qui augmente l'exposition et le risque d'inondation dans le ZML.

Mots-clés: Crues, susceptibilité, facteurs conditionnants, Zone Métropolitaine de Lisbonne, bassins-versants, zone inondable.

\section{INTRODUÇÃO}

Este artigo sintetiza parte de uma dissertação de mestrado (Leal, 2011), cujo objectivo central foi a avaliação da susceptibilidade às cheias de 12 pequenas bacias hidrográficas que drenam a Área Metropolitana de Lisboa (AML Norte): Colares, Vinhas, Caparide, Laje, Barcarena, Jamor, Trancão (bacia), Trancão (sub-bacia), Póvoa, Loures, Fanhões e Alpriate (fig. 1). Estas bacias têm sido afectadas com frequência por cheias rápidas, que provocam consideráveis danos directos (como vítimas mortais e danos físicos nas propriedades e infra-estruturas) e indirectos (como rupturas na rede de transportes e no comércio). Embora existam vários estudos sobre algumas destas bacias, não havia, até à referida dissertação, um estudo integrado e comparativo entre elas, que analisasse de que forma as suas características permanentes e variáveis interferem no seu comportamento face às cheias. Atendendo à janela temporal analisada (decenal), consideraram-se como características permanentes (factores de predisposição) as componentes físicas das bacias. Como características variáveis foram consideradas a ocupação humana do território e as mudanças no uso do solo. Esta foi a variável condicionante das cheias que se afigurou mais importante na AML Norte, dada a intensificação do processo de 
urbanização e de suburbanização que se verificou a partir da segunda metade do século XX e que contribuiu fortemente para as graves consequências das cheias rápidas de 1967, 1983 e 2008.

Procurou-se igualmente estimar os impactes das modificações do uso do solo no comportamento hidrológico das 12 bacias, nomeadamente nos tempos de concentração e nos caudais de ponta de cheia (que definem a magnitude das mesmas), bem como analisar a ocupação dos leitos de cheia e o seu processo de evolução nas últimas duas décadas, com base em informação digital para 1990 e 2006.

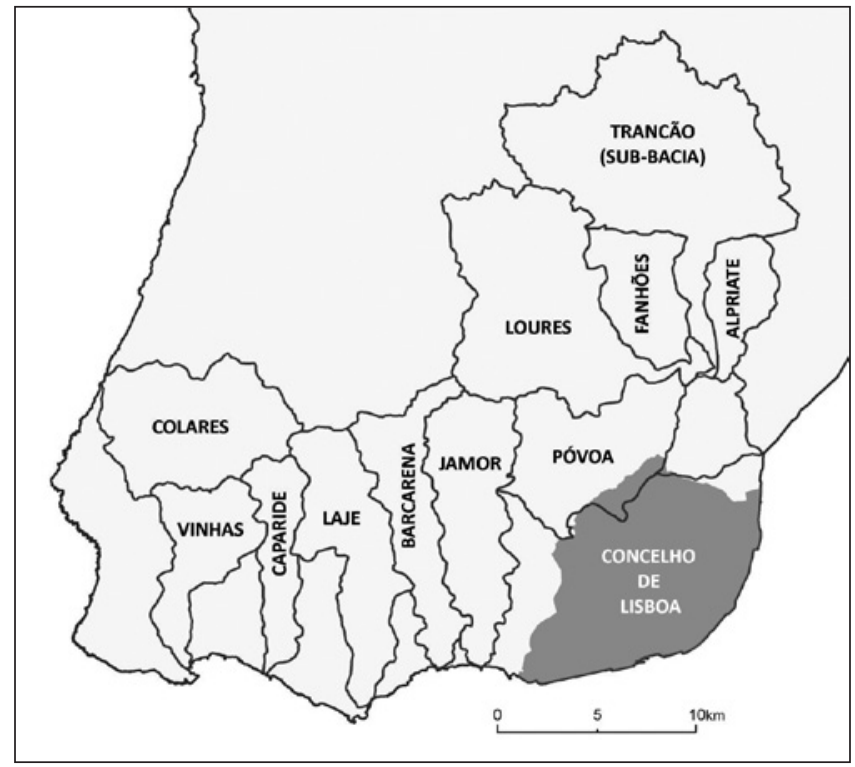

Fig. 1 - Bacias hidrográficas analisadas.

Fig. 1 -Drainage basins analysed.

\section{ENQUADRAMENTO TEÓRICO}

A susceptibilidade pode ser definida como a propensão de uma área para ser afectada por um determinado perigo, em tempo indeterminado, sendo avaliada através dos factores de predisposição para a ocorrência dos processos ou acções, não contemplando o seu período de retorno ou a probabilidade de ocorrência (Soeters e van Westen, 1996; Julião, 2009).

Esses factores influenciam a forma como as bacias hidrográficas respondem aos episódios de precipitação e determinam o seu grau de predisposição para serem afectadas por cheias. Neste trabalho apresenta-se uma concepção mais abrangente da susceptibilidade, porque aos factores de predisposição (geometria da bacia, rede de drenagem, relevo, substrato geológico e solos) se juntam factores variáveis (uso do solo e sua evolução). 
A influência das características físicas das bacias na amplificação ou na atenuação dos efeitos da precipitação é conhecida e aceite pela maioria dos autores. Genericamente, em bacias circulares, bem drenadas, com declives acentuados e de baixa permeabilidade ocorre um aumento na magnitude e na frequência das cheias, bem como uma diminuição nos tempos de concentração, em relação às que não possuem estas características (Patton, 1988; Smith e Ward, 1998; Lencastre e Franco, 2006; Ramos, 2009; NOAA, 2010). A análise das componentes permanentes passa pela sua quantificação, isto é, pelo cálculo de um conjunto de indicadores adimensionais que permite comparar bacias com áreas diferentes. Os primeiros estudos deste tipo foram efectuados por Horton na década de 30 do século XX. Actualmente, eles são realizados em todo o mundo, sem variação substancial dos indicadores utilizados. Porém, ao contrário do que sucede para a morfometria das bacias (que agrupa a geometria, o relevo e a rede de drenagem), no caso do substrato geológico e dos solos não existem indicadores que avaliem a permeabilidade, uma vez que ela é uma propriedade das formações geológicas, dependente da sua estrutura e textura (dimensão de espaços vazios). Por isso, essa avaliação é, geralmente, de forma qualitativa, comparando os litofácies das formações geológicas, ou recorrendo, por exemplo, aos números de escoamento (método do Soil Conservation Service). Uma outra forma de definir a permeabilidade de uma bacia é através de metodologias de carácter hidrogeológico, como as que sugerem Ramos (1994) e Ramos et al. (2010).

No que diz respeito à avaliação dos factores físicos, e especificamente para esta área de estudo, não existem muitos trabalhos. Reis (1996) efectuou uma análise morfológica da bacia da ribeira de Colares, à qual Lavrador-Silva (2002) acrescentou a identificação de pontos e troços de maior perigosidade às cheias e a avaliação da permeabilidade do substrato geológico. Essencialmente, estes dois autores consideraram que existem duas realidades dentro da bacia, uma vez que a margem esquerda apresenta uma susceptibilidade muito superior à da outra margem, pelas suas diferentes características litológicas, do relevo e da rede de drenagem. Sobre a bacia da ribeira da Póvoa/Odivelas, Borges et al. (2005) concluíram que esta possui condições muito favoráveis para a ocorrência de cheias rápidas, fazendo também uma avaliação da perigosidade.

O estudo dos factores variáveis pode ser efectuado de três formas distintas: 1) analisando apenas a ocupação do território numa determinada data, de modo a avaliar a influência antrópica no comportamento hidrológico da bacia face ao regime natural; 2) analisando a evolução entre duas ou mais datas, como fizeram Saraiva et al.(1998) para a bacia da ribeira da Laje, Lavrador-Silva (2002) para a bacia da ribeira de Colares e Borges et al. (2005) para a bacia da ribeira da Póvoa, de modo a caracterizar os impactes na permeabilidade da bacia; 3) analisando essa evolução e os seus impactes no regime hidrológico das bacias.

Quando o objectivo é estudar as cheias, o que mais importa examinar nos factores variáveis são as áreas edificadas/impermeabilizadas. Tal como acontece com os factores físicos, os efeitos da urbanização são conhecidos e resultam da impermeabilização dos solos a qual provoca o aumento da magnitude dos picos de escoamento e da frequência das cheias e a diminuição dos tempos de concentração. 
A estimativa dos tempos de concentração das bacias hidrográficas pode ser feita através de diversos métodos, ainda que o que melhores resultados apresenta para as bacias da região de Lisboa seja o de Temez (Correia, 1983).

Uma das formas de avaliar as modificações na resposta das bacias a eventos chuvosos é através de modelos hidrológicos, como o SWAT (Soil and Water Assessment Tool) ou o KINEROS (Kinematic Runoff and Erosion). Estes modelos permitem, principalmente, compreender o comportamento das bacias em termos hidrológicos, em função das suas características naturais e da acção humana (Miller et al., 2002). Quando se pretendem estimar os caudais de ponta de cheia e a influência das modificações no uso do solo, recorre-se aos métodos empíricos cinemáticos (Hipólito e Vaz, 2011). Destacam-se o Método Racional e o do Soil Conservation Service (SCS). O primeiro apresenta bons resultados em pequenas bacias hidrográficas (de algumas dezenas de $\mathrm{km}^{2}$ ), perdendo rigor à medida que a dimensão das bacias aumenta, enquanto o segundo é mais adequado para bacias com dimensões superiores aos valores referidos.

\section{METODOLOGIA}

De modo a obter a susceptibilidade das bacias hidrográficas às cheias foi necessário analisar individualmente os factores que a condicionam. Cada factor foi caracterizado através da selecção e quantificação de vários indicadores, que resultam do cruzamento de dois ou mais parâmetrosi (quadro I). Seguidamente, foram construídos três índices de susceptibilidade (natural, do uso do solo e do conjunto dos factores condicionantes) através do cruzamento e da ponderação numérica dos vários indicadores. Assim, de modo a obter a susceptibilidade natural das bacias foram quantificados: a geometria da bacia, o substrato geológico, o relevo e a rede de drenagem. Os solos não foram considerados porque a sua permeabilidade depende, em grande parte, das características hidrológicas da respectiva rocha-mãe. No caso do substrato geológico, a permeabilidade das formações geológicas varia entre 1 (permeabilidade mínima) e 9 (permeabilidade máxima) e foi definida em função da classificação das litologias existentes na AML (Ramos et al., 2010).

Quadro I - Indicadores utilizados para cada factor de predisposição às cheias.

Table I-Morphometric indicators used for each natural conditioning factor to floods.

\begin{tabular}{|c|c|c|c|}
\hline \multicolumn{4}{|c|}{ Factores naturais } \\
\hline Geometria & Substrato geológico & Relevo & Rede de drenagem \\
\hline $\begin{array}{l}\text { - Factor Forma } \\
\text { - Índice de Gravelius } \\
\text { - Índice de circularidade } \\
\text { - Índice de alongamento }\end{array}$ & $\begin{array}{l}\text { - \% área da bacia com } \\
\text { permeabilidade reduzida } \\
\text { (entre } 1 \text { e 4) } \\
\text { - \% área da bacia com } \\
\text { permeabilidade elevada } \\
\text { (entre 6 e 9) } \\
\text { - Permeabilidade média }\end{array}$ & $\begin{array}{l}\text { - Inclinação média do curso } \\
\text { de água principal } \\
\text { - Coeficiente orográfico } \\
\text { - Índice de rugosidade } \\
\text { - Relação de relevo } \\
\text { - Índice de declive de Roche }\end{array}$ & $\begin{array}{l}\text { - Densidade de drenagem } \\
\text { - Densidade hídrica } \\
\text { - Coeficiente de manutenção } \\
\text { - Coeficiente de } \\
\text { torrencialidade }\end{array}$ \\
\hline
\end{tabular}


Posteriormente, os resultados dos indicadores de cada uma das bacias foram divididos em quatro classes de igual amplitude, o que significa que as bacias têm valores/scores entre 1 (menor susceptibilidade) e 4 (maior susceptibilidade). Esses valores foram, de seguida, somados por factor e divididos pelo número total de indicadores de cada uma delas. Tomando como exemplo o factor geometria, os scores do factor forma, índice de Gravelius, índice de circularidade e índice de alongamento de cada bacia foram somados e, depois, divididos por quatro (o número de indicadores utilizados para a geometria). Optou-se por atribuir uma ponderação numérica de 1 à geometria e à rede de drenagem, de 2 ao relevo e de 3 ao substrato geológico, pelas seguintes razões: (i) o relevo é o factor decisivo na energia potencial da água e na velocidade do escoamento; apesar deste território não ser especialmente acidentado, existem algumas diferenças entre as bacias, nomeadamente no que diz respeito à altitude máxima e à amplitude altimétrica; (ii) o substrato geológico é considerado o factor mais importante, porque a permeabilidade da zona vadosa é a componente que mais interfere com a infiltração da água e, como tal, com a produção do escoamento superficial (Reis, 2006) e porque a rede de drenagem está essencialmente dependente das características do substrato geológico (Leopold, 1968; Ramos, 1994 e Reis, 2006), quando as bacias estão localizadas na mesma região climática (como é o caso), ou em contextos morfológicos semelhantes. Assim, a susceptibilidade natural das bacias hidrográficas pode ser obtida através da seguinte expressão:

$$
\operatorname{ISfp}=(1 * \mathrm{G}+3 * \mathrm{~S}+2 * \mathrm{R}+1 * \mathrm{D}) / 7
$$

em que:

ISfp = índice de susceptibilidade dos factores físicos (de predisposição); $\mathrm{G}=$ valor geometria; $\mathrm{S}=$ valor substrato geológico; $\mathrm{R}=$ valor relevo; $\mathrm{D}=$ valor rede de drenagem.

No que diz respeito aos factores variáveis das cheias, utilizou-se a cartografia Corine Land Cover de 1990 e de 2006, de modo a conhecer não só a ocupação do solo, mas também a sua evolução recente. As designações utilizadas no Corine Land Cover foram agrupadas em três classes em função da sua natureza: áreas edificadas, áreas agrícolas e áreas florestais e silvestres. Para classificar as bacias quanto à sua susceptibilidade às cheias foram calculados os seguintes indicadores: 1) percentagem da superfície ocupada por áreas edificadas na data mais recente (2006);2) percentagem de aumento dessas áreas entre 1990 e 2006; 3) percentagem da superfície ocupada por áreas florestais e silvestres em 2006.

Os passos seguintes são idênticos aos utilizados para os factores de predisposição, tendo sido atribuída uma ponderação numérica de 2 à percentagem de áreas edificadas, dada a importância das superfícies impermeabilizadas no contexto das cheias. A utilização das áreas florestais e silvestres na equação abaixo segue uma lógica inversa à das áreas edificadas, ou seja, às percentagens mais elevadas de áreas florestais e silvestres foram aplicados valores/scores mais baixos, uma vez que estas facilitam a infiltração da água ao contrário das áreas construídas que impermeabili- 
zam a superfície. A susceptibilidade ao uso do solo e sua evolução foi obtida através da seguinte fórmula:

$$
\text { ISfv }=(2 * A e+1 * \text { AumAe }+1 * A f s) / 4
$$

em que:

ISfv = índice de susceptibilidade dos factores variáveis; Ae $=$ valor das áreas edificadas em 2006 (\%); AumAe = valor do aumento das áreas edificadas entre 1990 e 2006 (\%); Afs = valor das áreas florestais e silvestres em 2006 (\%).

Tanto para os factores de predisposição como para os factores variáveis, recorreu-se à análise de clusters, que permite testar e validar a metodologia referida porque facilita a compreensão das relações de proximidade que se estabelecem entre as bacias.

O índice de susceptibilidade dos factores condicionantes foi alcançado através da seguinte expressão:

$$
\mathrm{ISfc}=(1 * \mathrm{G}+3 * \mathrm{~S}+2 * \mathrm{R}+1 * \mathrm{D}+3 * \mathrm{Us}) / 10
$$

em que:

ISfc $=$ índice de susceptibilidade dos factores condicionantes; $G=$ valor geometria; $\mathrm{S}=$ valor substrato geológico; $\mathrm{R}=$ valor relevo; $\mathrm{D}=$ valor rede de drenagem; Us = valor uso do solo em 2006 (resultado do ISfv).

Note-se que ao uso do solo foi atribuída uma ponderação numérica de 3, tal como ao substrato geológico, dado que ambos condicionam a permeabilidade das bacias hidrográficas.

Procurou-se igualmente compreender a evolução (1990-2006) dos usos do solo nas Zonas Afectadas por Cheias (ZAC), definidas pelo DL n ${ }^{\circ}$ 166/2008 e delimitadas em Ramos et al. (2010).

Para calcular o tempo de concentração das bacias hidrográficas foram utilizados os métodos de Temez (1978), por ser, como já foi referido, o que apresenta melhores resultados para a região de Lisboa (Correia, 1983), e o método do Federal Aviation Administration (FAA), que ao contrário do de Temez, permite entender o efeito que as mudanças do uso do solo têm no aumento da velocidade do escoamento. $\mathrm{O}$ método do FAA tem a seguinte fórmula:

$$
\mathrm{Tc}=\frac{3,26(1,1-\mathrm{C}) \mathrm{Ch}^{0,5}}{\mathrm{Db}^{0,333}}
$$

em que:

$\mathrm{Tc}=$ tempo de concentração (minutos); $\mathrm{C}=$ coeficiente de escoamento superficial (Carvalho, 1998); $\mathrm{Ch}=$ comprimento do curso de água principal (metros); $\mathrm{Db}=$ declive médio da bacia $(\%)$.

Para se estimar a influência do uso do solo nos caudais de ponta atingidos nas cheias de Fevereiro de 2008 utilizou-se o Método Racional, recorrendo aos dados 
horários de precipitação de algumas estações da rede do INAG. Este método, cuja fórmula é atribuída a Mulvaney em meados do século XIX, é um dos mais utilizados para o cálculo dos caudais de ponta de cheia em bacias hidrográficas de pequena dimensão (Hipólito e Vaz, 2011), como é o caso das da AML Norte.

\section{FACTORES DE PREDISPOSIÇÃO ÀS CHEIAS}

Todas as bacias hidrográficas da AML Norte podem ser consideradas pequenas, já que as suas áreas variam entre as dezenas e as duas ou três centenas de $\mathrm{km}^{2}$ (quadro II). Quanto à forma, à primeira vista, existem dois conjuntos de bacias distintos: as arredondadas, compostas pela bacia da ribeira de Colares e pela bacia e respectivas sub-bacias do rio Trancão e as alongadas da costa do Estoril (Vinhas, Caparide, Laje, Barcarena e Jamor) (fig. 1).

Os resultados dos indicadores calculados e do índice final da geometria estão presentes no quadro II. Assim, Colares, Fanhões e Póvoa são, claramente, as bacias mais favoráveis à ocorrência de cheias, seguidas da bacia de Alpriate. Caparide e Barcarena são muito pouco propensas à ocorrência de cheias no que respeita à componente geometria.

Quadro II - Indicadores referentes à geometria das bacias

(indicadores da susceptibilidade em duas colunas: a primeira de resultados e a segunda dos scores). Table II - Basins geometry indicators (the indicators of the susceptibility are shown in two columns: the first one pertains to the results and the second one to the scores).

\begin{tabular}{|c|c|c|c|c|c|c|c|c|c|c|c|c|}
\hline \multirow{2}{*}{$\begin{array}{c}\text { Bacias } \\
\text { hidrográficas }\end{array}$} & \multirow{2}{*}{$\begin{array}{r}\begin{array}{r}\text { Área } \\
\left(\mathrm{km}^{2}\right)\end{array} \\
34,5\end{array}$} & \multirow{2}{*}{$\begin{array}{c}\begin{array}{c}\text { Perímetro } \\
(\mathrm{km})\end{array} \\
42,9\end{array}$} & \multirow{2}{*}{$\begin{array}{c}\begin{array}{c}\text { Comprimento } \\
(\mathrm{km})\end{array} \\
14,5\end{array}$} & \multicolumn{2}{|c|}{$\begin{array}{c}\text { Factor forma } \\
\text { (Horton) }\end{array}$} & \multicolumn{2}{|c|}{$\begin{array}{l}\text { Índice de } \\
\text { Gravelius }\end{array}$} & \multicolumn{2}{|c|}{$\begin{array}{l}\text { Índice de } \\
\text { circularidade } \\
\text { (Miller) }\end{array}$} & \multicolumn{2}{|c|}{$\begin{array}{l}\text { Índice de } \\
\text { alongamento } \\
\text { (Schumm) }\end{array}$} & \multirow{2}{*}{$\begin{array}{c}\begin{array}{c}\text { Valor índice } \\
\text { (geometria) }\end{array} \\
1,0\end{array}$} \\
\hline & & & & 0,16 & 1 & 2,04 & 1 & 0,24 & 1 & 0,46 & 1 & \\
\hline Caparide & 20,5 & 28,5 & 11,0 & 0,17 & 1 & 1,76 & 2 & 0,32 & 1 & 0,46 & 1 & 1,3 \\
\hline Colares & 50,4 & 33,4 & 10,0 & 0,50 & 4 & 1,32 & 4 & 0,57 & 4 & 0,80 & 4 & 4,0 \\
\hline Jamor & 43,8 & 39,3 & 13,9 & 0,23 & 1 & 1,66 & 3 & 0,36 & 2 & 0,54 & 1 & 1,8 \\
\hline Laje & 41,7 & 39,7 & 13,2 & 0,24 & 1 & 1,72 & 2 & 0,33 & 2 & 0,55 & 1 & 1,5 \\
\hline Vinhas & 27,3 & 30,2 & 9,3 & 0,31 & 2 & 1,62 & 3 & 0,38 & 2 & 0,63 & 2 & 2,3 \\
\hline Alpriate & 17,3 & 19,7 & 7,5 & 0,31 & 2 & 1,33 & 4 & 0,56 & 4 & 0,63 & 2 & 3,0 \\
\hline Fanhões & 25,6 & 24,4 & 6,7 & 0,56 & 4 & 1,35 & 4 & 0,54 & 4 & 0,85 & 4 & 4,0 \\
\hline Loures & 81,3 & 55,1 & 14,4 & 0,39 & 3 & 1,71 & 2 & 0,34 & 2 & 0,71 & 3 & 2,5 \\
\hline Póvoa & 45,2 & 36,1 & 9,2 & 0,54 & 4 & 1,50 & 4 & 0,44 & 3 & 0,83 & 4 & 3,8 \\
\hline Trancão (SB)* & 104,7 & 66,1 & 15,9 & 0,42 & 3 & 1,81 & 2 & 0,30 & 1 & 0,73 & 3 & 2,3 \\
\hline Trancão (B) & 290,8 & 95,0 & 20,3 & 0,7 & & 1,5 & & 0,4 & & 0,95 & & \\
\hline
\end{tabular}

* Trancão (SB) e Trancão (B): Sub-bacia do Trancão e Bacia do Trancão, respectivamente.

Susceptibilidade às cheias: 
A diferença de predisposição às cheias entre Loures/Trancão (SB) e as primeiras classificadas do ranking, explica-se porque estas duas bacias são bastante mais estreitas nos sectores terminais (fig. 1). No caso da bacia da ribeira das Vinhas, apesar de parecer uma bacia alongada, a susceptibilidade é moderada porque o seu sector montante é substancialmente mais amplo do que os sectores intermédio e jusante (fig. 1).

Os resultados obtidos foram confirmados pela análise de clusters (fig. 2), cujo corte de hierarquia superior do dendograma confirma a separação das bacias de drenagem em dois grandes grupos: bacias com predisposição às cheias elevada a muito elevada e bacias com predisposição moderada a muito reduzida.

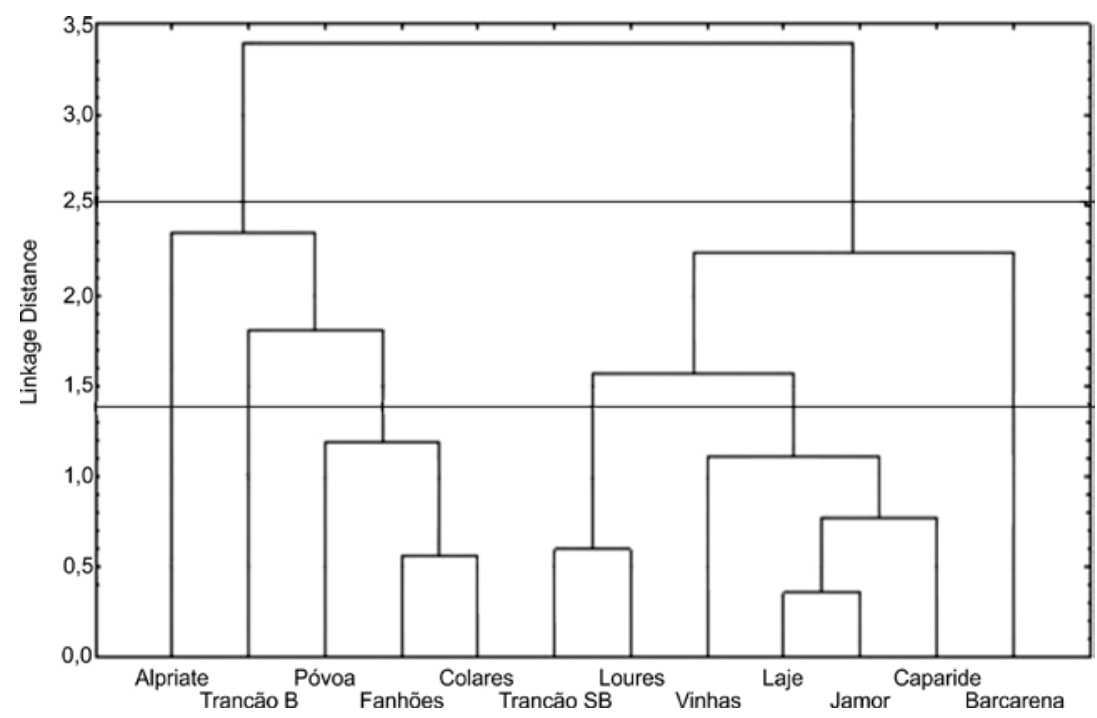

Fig. 2 - Análise de clusters (geometria) para as bacias hidrográficas.

Fig. 2 - Cluster analysis for the basins'geometry.

Na AML Norte existe uma grande diversidade litológica, uma vez que, além das rochas sedimentares, também ocorrem as magmáticas, como as que compõem o maciço de Sintra e o Complexo Vulcânico de Lisboa. Se o tipo e as características das rochas é diferente, também a sua permeabilidade será distinta, o que se irá reflectir no grau de predisposição às cheias das bacias hidrográficas ${ }^{\mathrm{iii}}$.

O quadro III mostra que Fanhões, Póvoa e Trancão (SB) possuem uma predisposição muito elevada. As duas primeiras bacias são formadas, maioritariamente, por materiais do Complexo Vulcânico de Lisboa (muito alterados) e pelas aluviões argilosas da depressão de Loures (formações de permeabilidade baixa e muito baixa). Trancão (SB) desenvolve-se, em quase toda a sua extensão, sobre formações sedimentares com margas na sua composição, o que lhes reduz significativamente a permeabilidade. 
Quadro III - Indicadores referentes ao substrato geológico das bacias (divididos em duas colunas: a primeira de resultados e a segunda dos scores).

Table III - Basins geology indicators

(shown in two columns: the first one with the results and the second one with the scores).

\begin{tabular}{|c|c|c|c|c|}
\hline $\begin{array}{c}\text { Bacias } \\
\text { hidrográficas }\end{array}$ & $\begin{array}{l}\text { Áreas de } \\
\text { permeabilidade } \\
\text { reduzida ou muito } \\
\text { reduzida }(\%)\end{array}$ & $\begin{array}{c}\text { Áreas de } \\
\text { permeabilidade } \\
\text { elevada ou muito } \\
\text { elevada }(\%)\end{array}$ & $\begin{array}{l}\text { Permeabilidade } \\
\text { média }\end{array}$ & $\begin{array}{c}\text { Valor índice } \\
\text { (substrato } \\
\text { geológico) }\end{array}$ \\
\hline Barcarena & $53,8 \quad 2$ & $19,9 \quad 3$ & $4,05 \quad 3$ & 2,7 \\
\hline Caparide & $36,4 \quad 1$ & $29,7 \quad 1$ & $4,66 \quad 1$ & 1,0 \\
\hline Colares & $44,2 \quad 2$ & $24,9 \quad 2$ & $4,56 \quad 1$ & 1,7 \\
\hline Jamor & $49,9 \quad 2$ & $24,1 \quad 2$ & $3,96 \quad 3$ & 2,3 \\
\hline Laje & $24,5 \quad 1$ & $36,8 \quad 1$ & $4,79 \quad 1$ & 1,0 \\
\hline Vinhas & $57,8 \quad 3$ & $30,4 \quad 1$ & $3,92 \quad 3$ & 2,3 \\
\hline Alpriate & $61,4 \quad 3$ & $25,3 \quad 2$ & $4,16 \quad 2$ & 2,3 \\
\hline Fanhões & $65,6 \quad 3$ & $13,2 \quad 4$ & $3,43 \quad 4$ & 3,7 \\
\hline Loures & $52,9 \quad 2$ & $6,1 \quad 4$ & $3,79 \quad 3$ & 3,0 \\
\hline Póvoa & $70,2 \quad 4$ & $17,8 \quad 3$ & $3,70 \quad 4$ & 3,7 \\
\hline Trancão (SB) & $84,6 \quad 4$ & $6,4 \quad 4$ & $4,20 \quad 2$ & 3,3 \\
\hline Trancão (B) & 62,1 & 18,0 & 4,15 & \\
\hline
\end{tabular}

Susceptibilidade às cheias:

Muito reduzida

$\square$ Reduzida

Moderada

Elevada

Muito elevada

A classe seguinte engloba Loures e Barcarena, bacias com áreas relativamente extensas ocupadas pelo Complexo Vulcânico de Lisboa, embora não tão extensas como acontece nas três primeiras do ranking.

Com predisposição moderada surgem Jamor, Alpriate e Vinhas. Quanto a Alpriate, apesar de boa parte da sua área estar sobre o Complexo Vulcânico de Lisboa, as aluviões da depressão de Loures e o Complexo de Benfica (permeabilidade baixa), têm também formações com permeabilidades elevadas (areias, areolas e outras formações de origem sedimentar). A bacia de Vinhas tem, no sector montante, um substrato geológico de baixa a muito baixa permeabilidade (granitos de Sintra e calcários e margas - formação de Ramalhão), mas a restante bacia é constituída por formações de permeabilidades médias e elevadas.

Colares, Caparide e Laje têm uma predisposição às cheias reduzida a muito reduzida. No caso das duas últimas, o substrato geológico é formado, predominantemente, por rochas sedimentares (calcários, arenitos, margas e conglomerados) que, no geral, apresentam permeabilidades médias e elevadas. O caso de Colares é um pouco diferente, já que existe uma dissimetria entre as duas margens do curso de água principal no que respeita às características das rochas. A margem esquerda é composta quase exclusivamente por granitos e sienitos (permeabilidade muito reduzida), enquanto a margem direita possui uma extensa área de calcários e arenitos 
(permeabilidade elevada). Por outro lado, a parte jusante desta bacia é coberta por formações dunares (permeabilidade muito elevada).

A análise de clusters valida a maioria das conclusões alcançadas. O corte de hierarquia superior na figura 3 possibilita a separação das bacias com predisposições às cheias reduzidas e muito reduzidas (Colares, Caparide e Laje) em relação às restantes. Quanto ao corte inferior do dendograma, permite distinguir três grupos de bacias: 1) de predisposição reduzida e muito reduzida; 2) de predisposição elevada e muito elevada (Loures, Póvoa e Fanhões); 3) de predisposição moderada (Vinhas, Alpriate e Jamor).

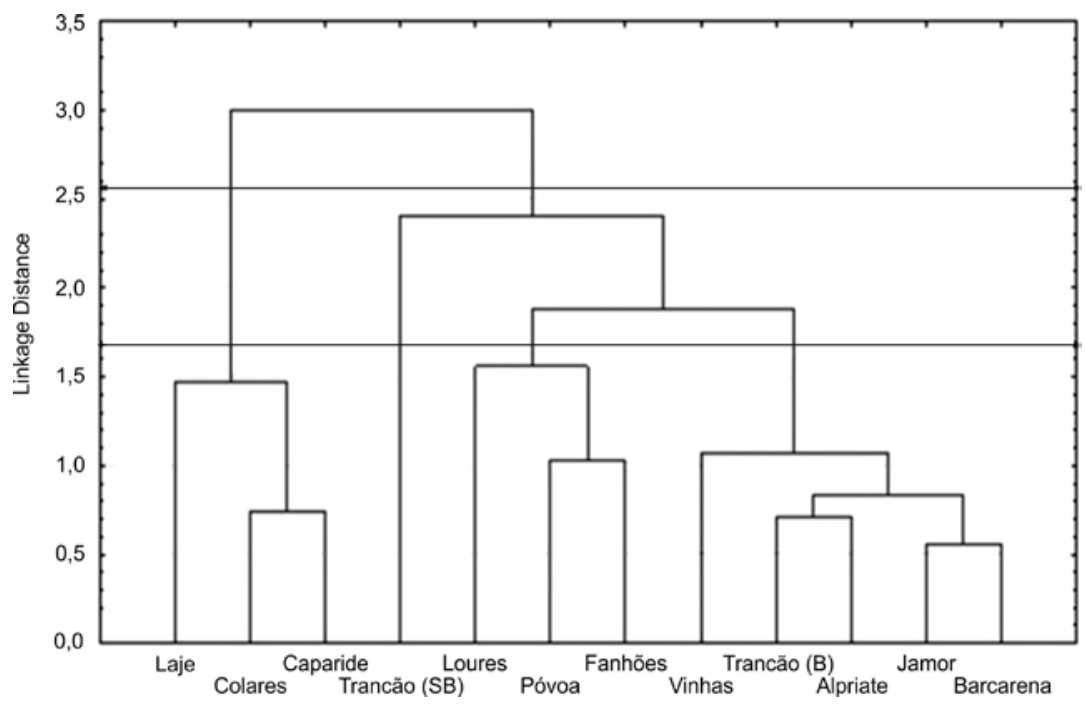

Fig. 3 - Análise de clusters (substrato geológico) para as bacias hidrográficas.

Fig. 3 - Cluster analysis for the geology of the basins.

Do ponto de vista do relevo, a AML Norte não é um território muito acidentado. Dominam os relevos em estrutura monoclinal (costeiras e elementos planálticos, os quais correspondem, nuns casos, a superfícies subestruturais e, noutros, de arrasamento), destacando-se claramente a serra de Sintra, pela sua génese e composição litológica, tornando as ribeiras que drenam a partir deste maciço mais propensas à ocorrência de cheias rápidas. O quadro IV comprova a existência de duas realidades completamente distintas. Existem cinco bacias (Vinhas, Caparide, Fanhões, Alpriate e Colares) que se diferenciam das restantes. Às três bacias que escoam a partir do maciço de Sintra, juntam-se Fanhões e Alpriate. Esta situação explica-se porque estas duas bacias se localizam no reverso da costeira de Lousa-Bucelas, apresentando amplitudes altimétricas significativas tendo em conta a sua reduzida dimensão. No entanto, existem diferenças entre elas ao nível do índice finnal do relevo. Vinhas é a bacia com o grau de predisposição às cheias, mais elevado, porque o comprimento é reduzido e a amplitude altimétrica muito significativa (quadro IV). 


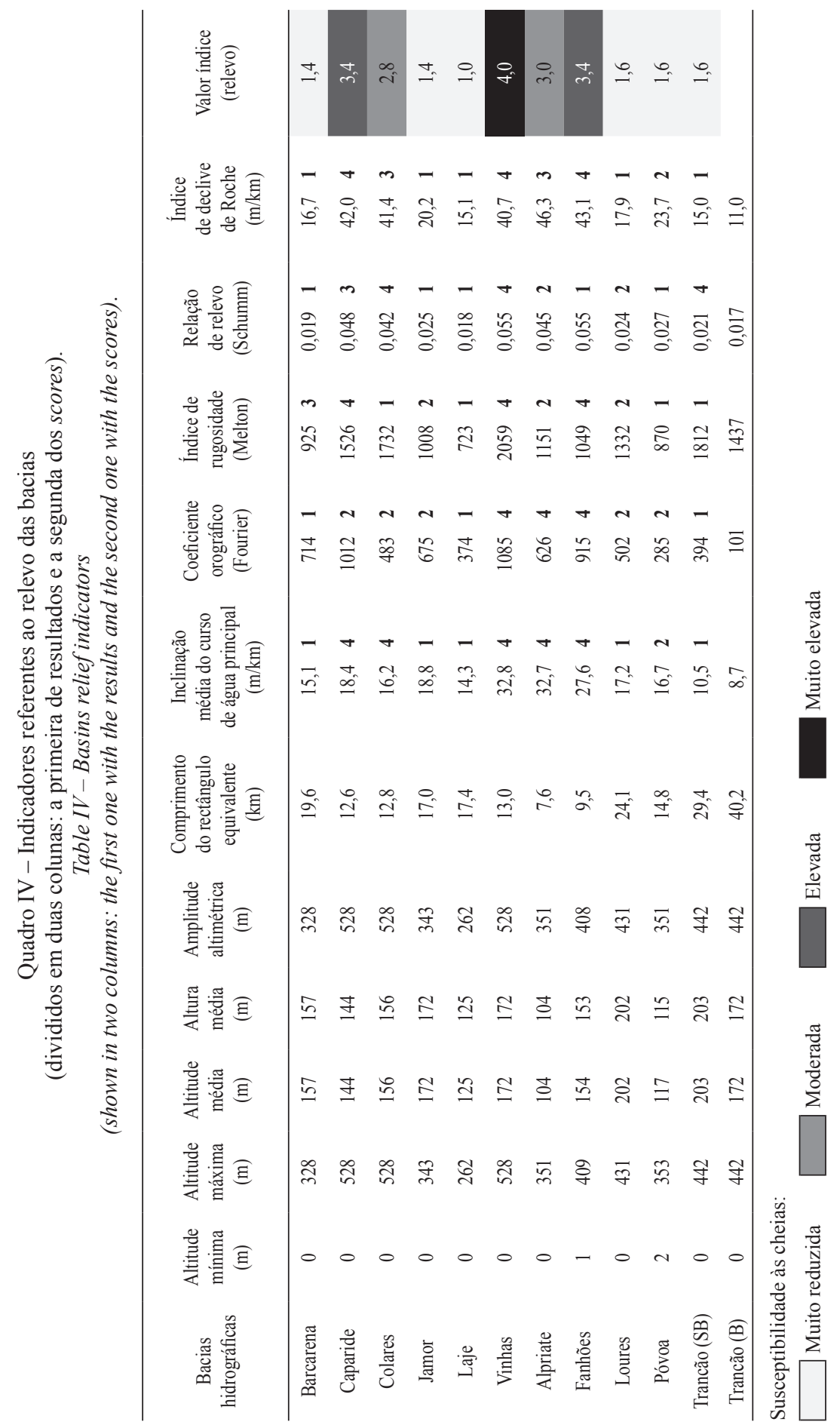


Loures, Póvoa, Trancão (SB), Barcarena, Jamor e Laje enquadram-se na classe de predisposição muito reduzida. A distância entre os dois grupos de bacias, acima definidos, reflecte-se na ausência da classe de susceptibilidade reduzida, que a análise de clusters também comprova (fig.4).

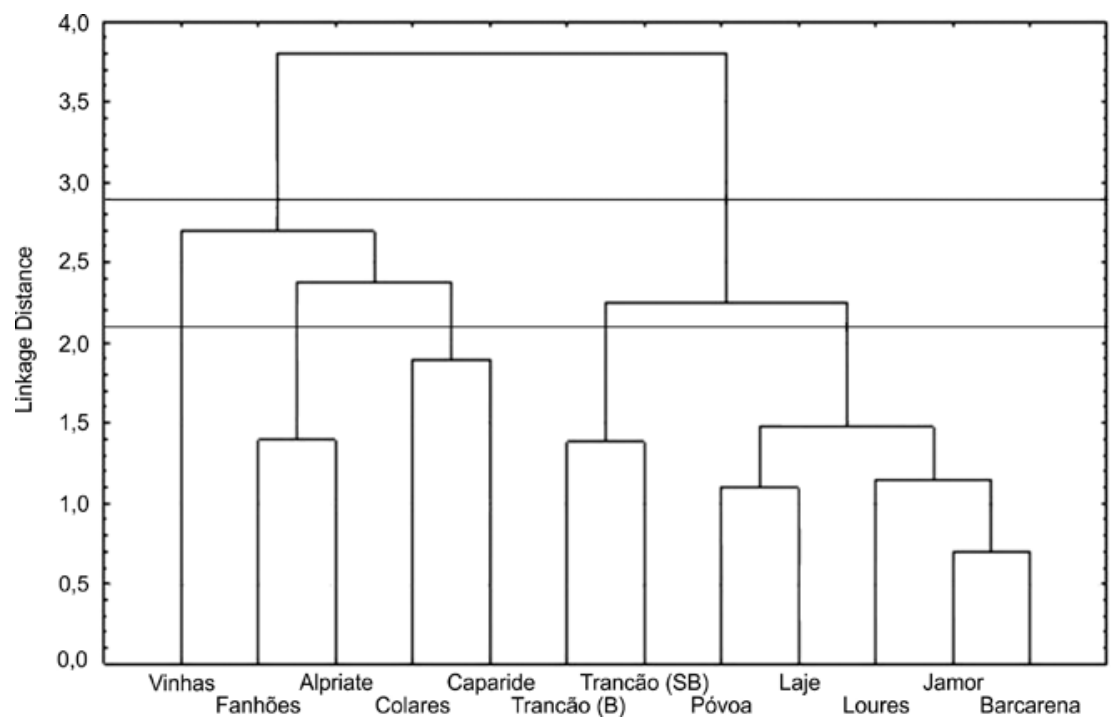

Fig. 4 - Análise de clusters (relevo) para as bacias hidrográficas.

Fig. 4 - Cluster analysis for the relief of the basins.

Como já foi dito, a rede de drenagem está muito dependente das características de permeabilidade da zona vadosa. Recorrendo aos valores da densidade de drenagem (quadro $\mathrm{V}$ ) pode dizer-se que nenhuma das bacias hidrográficas estudadas pode ser considerada mal drenada.

Analisando o factor rede de drenagem, observa-se uma grande disparidade entre as bacias do Trancão (SB) e Vinhas e as restantes (quadro V). Estas duas bacias possuem uma predisposição às cheias muito elevada, uma vez que o escoamento superficial se organiza rapidamente (ver os valores do coeficiente de manutenção no quadro V), potenciando a magnitude da rede e respectiva hierarquização, que, por sua vez, dada a reduzida dimensão das bacias, favorece a boa drenagem (elevadas densidades hídrica e de drenagem). Esta diferença é de tal forma notória, entre estas duas bacias e as outras, que a classe de predisposição elevada não existe. 


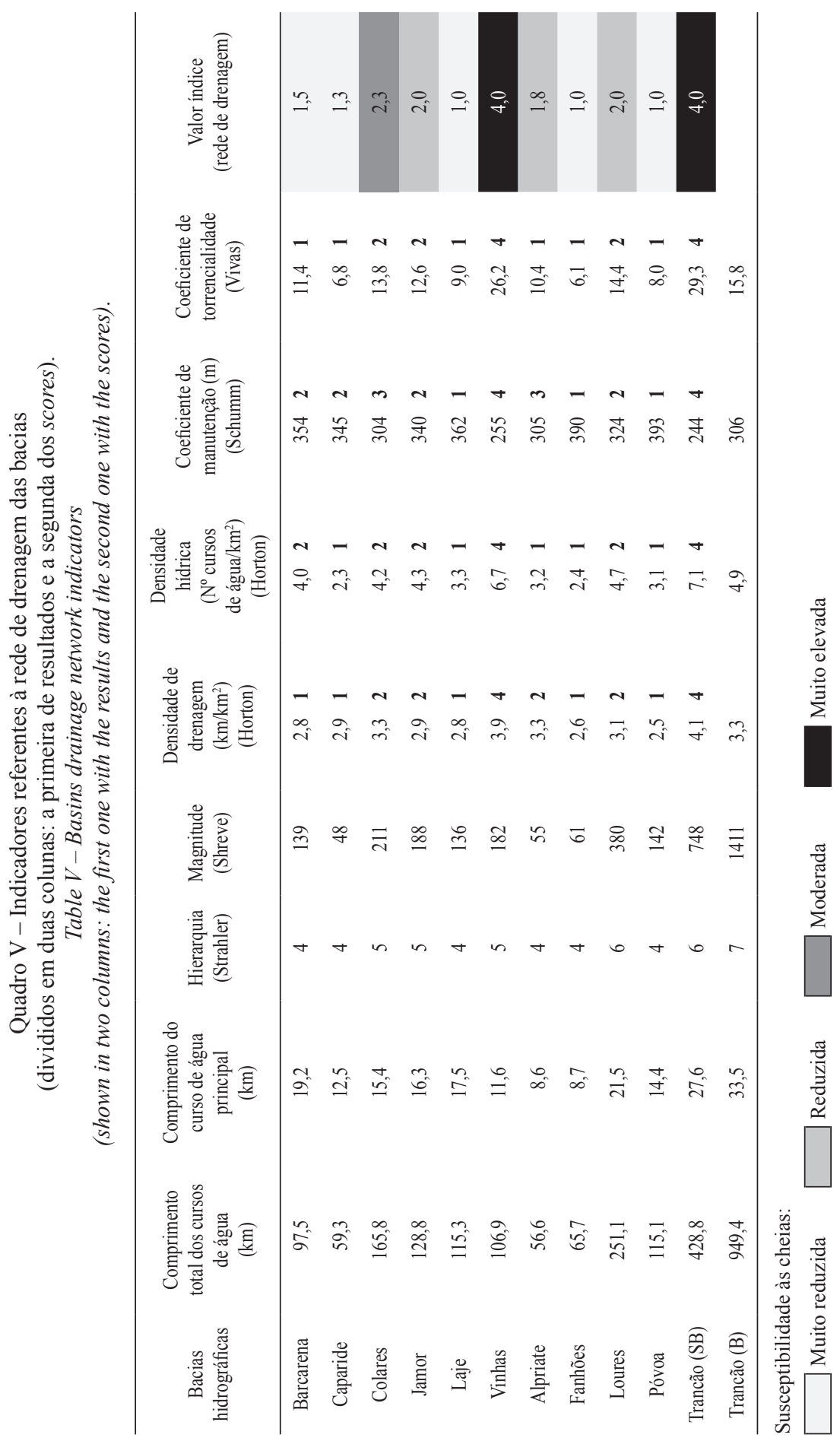


A análise de clusters confirma, claramente, esta diferença (fig. 5).

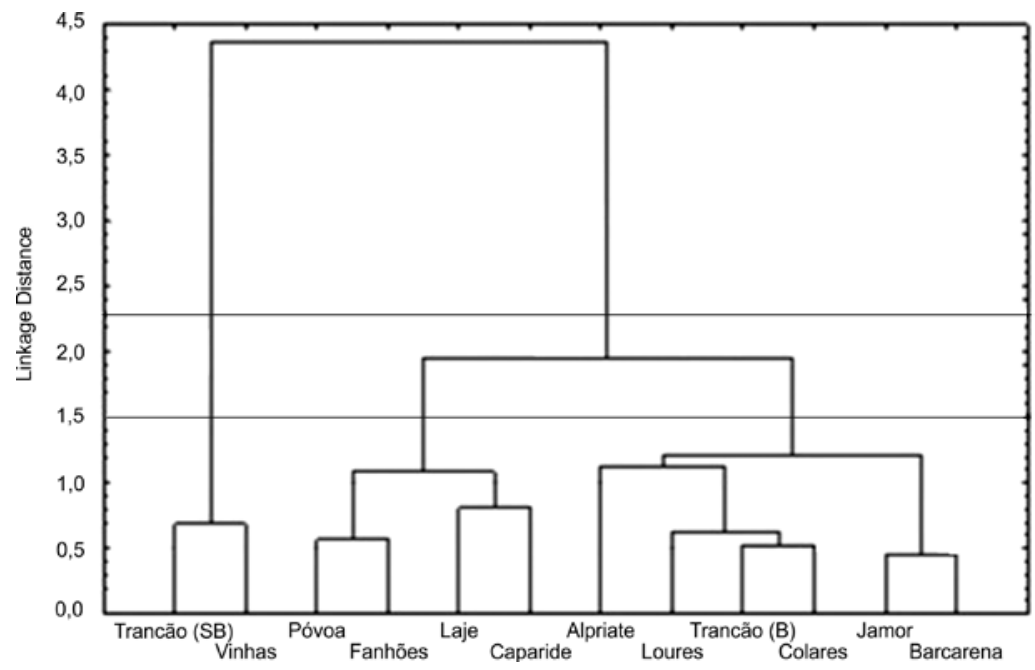

Fig. 5 - Análise de clusters (rede de drenagem) para as bacias hidrográficas.

Fig. 5 -Cluster analysis for the drainage network of the basins.

Depois de analisadas individualmente, as quatro componentes naturais das bacias hidrográficas (factores de predisposição) foram combinadas de modo a obter uma classificação de susceptibilidade natural às cheias. Os resultados do índice de susceptibilidade dos factores de predisposição (ISfp) são apresentados no quadro VI e na figura 6.

\begin{tabular}{ccc}
\hline \multicolumn{3}{c}{ Factores Naturais } \\
\hline Posição & Bacia hidrográfica & ISfp \\
\hline $1^{\circ}$ & Fanhões & 3,3 \\
$2^{\circ}$ & Vinhas & 3,0 \\
$3^{\circ}$ & Trancão (SB) & 2,8 \\
$4^{\circ}$ & Póvoa & 2,7 \\
$5^{\circ}$ & Alpriate & 2,5 \\
$6^{\circ}$ & Colares & 2,4 \\
& Loures \\
$8^{\circ}$ & Jamor & 1,9 \\
& Barcarena & 1,8 \\
$10^{\circ}$ & Caparide & 1,1 \\
\hline $11^{\circ}$ & Laje
\end{tabular}

Quadro VI - Índice de susceptibilidade natural às cheias.

Table VI-Natural susceptibility index to floods.

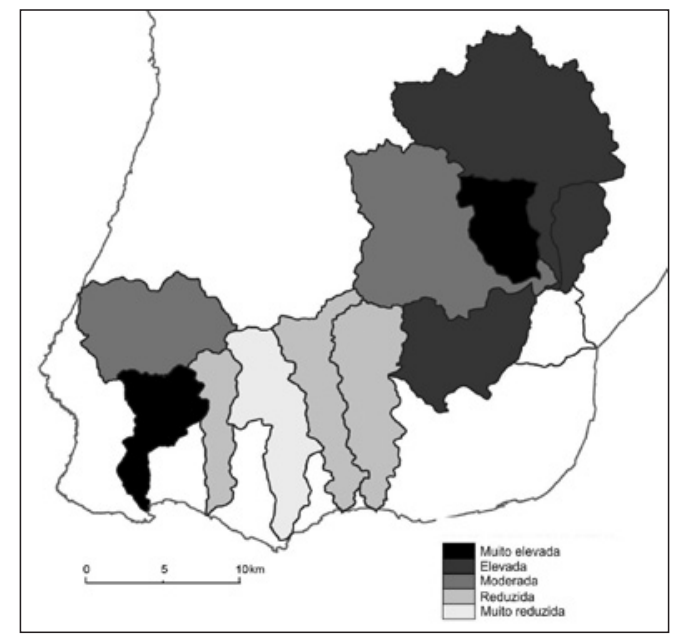

Fig. 6 - Susceptibilidade natural às cheias das bacias.

Fig. 6-Basins natural susceptibility to floods. 
Fanhões é a bacia mais susceptível às cheias devido, à influência conjunta do substrato geológico, da geometria e do relevo. A bacia de Vinhas tem igualmente uma susceptibilidade muito elevada devido às características do relevo e da rede de drenagem. Os valores do índice de susceptibilidade natural mais baixos são os de Jamor, Barcarena, Caparide e Laje, que, como se viu durante a análise factor a factor, são as bacias de menor predisposição a este fenómeno hidrológico. Laje é a única bacia com susceptibilidade muito reduzida, até porque nenhum dos factores físicos é particularmente agravante no condicionamento às cheias.

\section{FACTORES VARIÁVEIS: A ACÇÃO HUMANA NO TERRITÓRIO}

\section{Mudanças no uso do solo}

A partir da segunda metade do século XX, a AML registou um forte aumento das áreas edificadas, em parte devido ao desenvolvimento das áreas urbanas de génese ilegal (AUGI) (Borges et al., 2005). Este processo de urbanização acarretou consequências no que diz respeito à susceptibilidade e vulnerabilidade às cheias.

A figura 7 retrata o uso do solo em 2006 nas várias bacias hidrográficas analisadas. Verifica-se que existem bacias com uma ocupação dominantemente urbana (Póvoa, Jamor, Barcarena, Laje e Caparide), bacias maioritariamente agrícolas (Loures, Trancão (SB) e Fanhões) e outras dominantemente florestais (Vinhas e Colares). Em Alpriate, as áreas urbanas e as áreas florestais ocupavam, em 2006, superfícies semelhantes.

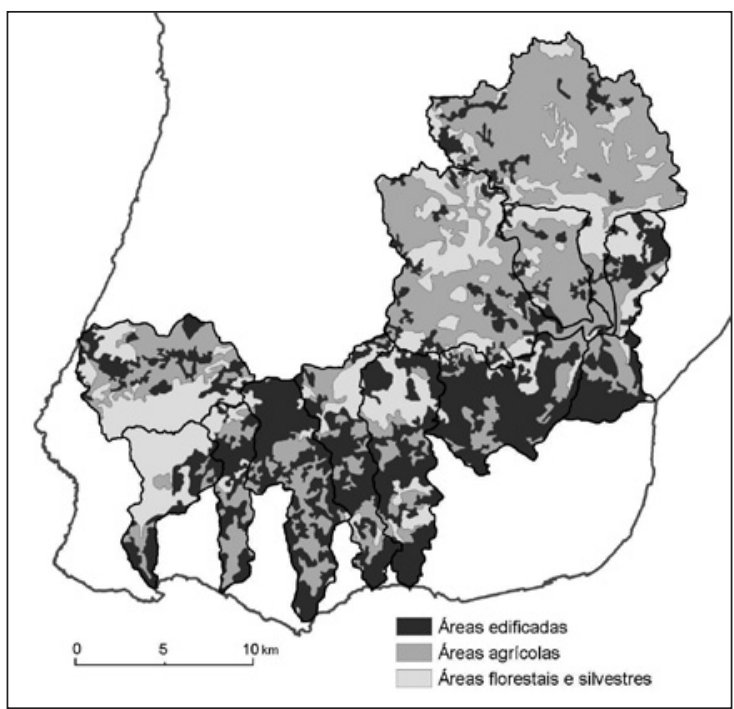

Fig. 7 - Uso do solo nas bacias hidrográficas (2006).

Fig. 7 -Drainage basins land use (2006). 
Analisando com maior detalhe as áreas com ocupação dominantemente urbana, verifica-se que, em 2006, estas representavam mais de 70\% da superfície da bacia da ribeira da Póvoa, à qual se seguiam as bacias da Laje (64\%), Jamor (53\%), Barcarena (50\%), Caparide (46\%) e Alpriate (41\%) (quadro VII). Embora se tenham registado aumentos das áreas edificadas em todas as bacias, o crescimento urbano, em apenas 16 anos (1990 - 2006), foi muito rápido nas bacias da Laje (28\%) e de Alpriate (26\%; quadro VII), cujas áreas edificadas representavam apenas $15 \%$ do seu território em 1990. Por outro lado, os dados apurados revelam que os acréscimos nas áreas edificadas ocorreram, maioritariamente, à custa das áreas agrícolas, com excepção das bacias de Colares e de Alpriate, devido ao seu cariz florestal.

Quadro VII - Indicadores do uso do solo nas diversas bacias

(divididos em duas colunas: a primeira de resultados e a segunda dos scores).

Table VII - Basins land use indicators

(shown in two columns: the first one with the results and the second one with the scores).

\begin{tabular}{|c|c|c|c|}
\hline $\begin{array}{c}\text { Bacias } \\
\text { hidrográficas }\end{array}$ & $\begin{array}{c}\text { Áreas edificadas } \\
2006 \\
(\%)\end{array}$ & $\begin{array}{c}\text { Aumento áreas edificadas } \\
\text { 1990-2006 } \\
(\%)\end{array}$ & $\begin{array}{c}\text { Áreas florestais e silvestres } \\
2006 \\
(\%)\end{array}$ \\
\hline Barcarena & $50,3 \quad 3$ & $20,5 \quad 3$ & $21,2 \quad 3$ \\
\hline Caparide & $45,8 \quad 3$ & $20,6 \quad 3$ & $15,8 \quad 4$ \\
\hline Colares & $22,4 \quad 1$ & $4,0 \quad 1$ & $43,7 \quad 2$ \\
\hline Jamor & $53,3 \quad 3$ & $20,1 \quad 3$ & $29,7 \quad 3$ \\
\hline Laje & $64,0 \quad 4$ & $28,1 \quad 4$ & $3,7 \quad 4$ \\
\hline Vinhas & $29,9 \quad 2$ & $7,8 \quad 1$ & $57,8 \quad 1$ \\
\hline Alpriate & $41,3 \quad 3$ & $26,0 \quad 4$ & $43,5 \quad 2$ \\
\hline Fanhões & $15,0 \quad 1$ & $5,6 \quad 1$ & $23,0 \quad 3$ \\
\hline Loures & $13,7 \quad 1$ & $3,3 \quad 1$ & $31,8 \quad 2$ \\
\hline Póvoa & $70,6 \quad 4$ & $18,6 \quad 3$ & $9,5 \quad 4$ \\
\hline Trancão (SB) & $8,8 \quad 1$ & $3,4 \quad 1$ & 20,1 \\
\hline Trancão (B) & 25,8 & 7,6 & 22,4 \\
\hline
\end{tabular}

A partir dos valores do índice de susceptibilidade dos factores variáveis (ISfv, quadro VIII e fig. 8) e da análise de clusters, verifica-se que existe uma distinção evidente nos tipos de ocupação do território contrastados: as bacias com uso do solo dominantemente urbano (Laje, Póvoa, Caparide, Alpriate, Barcarena e Jamor) e as bacias com uso agrícola e/ou florestal/silvestre (Fanhões, Trancão (SB), Vinhas, Colares e Loures). Estas últimas possuem uma susceptibilidade muito reduzida às cheias, enquanto a susceptibilidade é moderada em Alpriate, em Barcarena e no Jamor, é elevada em Caparide e é muito elevada na Laje e na Póvoa. Estas duas últimas bacias foram consideradas as mais susceptíveis, já que são as que têm maior superfície impermeabilizada, as que têm menor superfície florestal e silvestre e também as que registaram dos maiores crescimentos urbanos entre 1990 e 2006. 


\begin{tabular}{ccc}
\hline \multicolumn{3}{c}{ Factores Variáveis } \\
\hline Posição & Bacia hidrográfica & ISFV \\
\hline $1^{\circ}$ & Laje & 4,0 \\
$2^{\text {o }}$ & Póvoa & 3,8 \\
$3^{\text {o }}$ & Caparide & 3,3 \\
& Alpriate & \\
$4^{\circ}$ & Barcarena & 3,0 \\
& Jamor & \\
& Fanhões \\
$7^{\circ}$ & Trancão (SB) & 1,5 \\
& Vinhas \\
$10^{\circ}$ & Colares \\
& Loures & 1,3 \\
\hline
\end{tabular}

Quadro VIII - Índice de susceptibilidade das bacias às cheias, devido ao uso do solo e sua evolução.

Table VIII - Basins susceptibility index

to flooding due to land use changes.

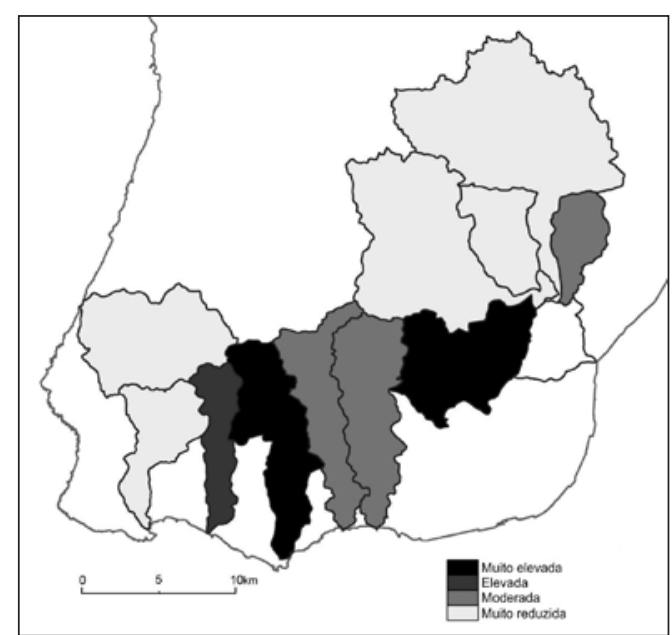

Fig. 8 - Susceptibilidade das bacias às cheias devido ao uso do solo e sua evolução.

Fig. 8 -Basins susceptibility to flooding due to changes in land use.

\section{Influência das mudanças do uso do solo nos tempos de concentração e nos caudais de ponta de cheia}

O tempo de concentração de uma bacia de drenagem define-se como o tempo que uma partícula de água demora a atingir a secção de referência, partindo do ponto cinematicamente mais afastado (Lima J e Lima I, 2010). Por outras palavras, é o tempo necessário para que toda a área da bacia contribua para o escoamento superficial na desembocadura (Lencastre e Franco, 2006). Com recurso ao método de Temez (1978) os resultados dos tempos de concentração apontam para valores inferiores a 6 horas na maioria das bacias, o que traduz a sua potencial capacidade para gerar cheias rápidas.

De modo a avaliar a influência da ocupação humana nos tempos de concentração das bacias utilizou-se o método do Federal Aviation Administration (FAA). Apesar de estimar os resultados por defeito, uma vez que é, por norma, aplicado em bacias fortemente urbanizadas, este método permite conhecer as modificações relativas dos tempos de concentração entre dois períodos de referência (neste caso entre 1990 e 2006; quadro IX). A bacia da ribeira da Laje destaca-se de todas as outras, pela expansão muito rápida das áreas edificadas e consequente diminuição das áreas agrícolas. O tempo de concentração desta bacia baixou quase $16 \%$ em 16 anos. Adicionalmente, existem outras bacias em que se verificam reduções significativas: Barcarena (10\%), Caparide (8\%), Jamor (8\%), Alpriate (7\%) e Póvoa (6\%). Como seria de esperar, as diminuições dos tempos de concentração são menos notórias nas bacias hidrográficas dominantemente agrícolas e florestais. 
Quadro IX - Tempos de concentração das bacias hidrográficas (TP), segundo os métodos de Temez e FAA, e variação segundo este último entre 1990 e 2006.

Table IX-Concentration times of the basins (TP) according to the Temez and FAA method, and variation of the latter between 1990 and 2006.

\begin{tabular}{|c|c|c|c|c|}
\hline Bacias hidrográficas & $\begin{array}{c}\text { TP } \\
\text { (Temez) }\end{array}$ & $\begin{array}{c}\mathrm{TP} \\
\text { (FAA) } \\
1990\end{array}$ & $\begin{array}{c}\mathrm{TP} \\
(\mathrm{FAA}) \\
2006\end{array}$ & $\begin{array}{c}\text { Redução do TP } \\
\text { 1990-2006 }\end{array}$ \\
\hline Barcarena & $06 \mathrm{~h} 17 \mathrm{~m}$ & $04 \mathrm{~h} 02 \mathrm{~m}$ & $03 \mathrm{~h} 38 \mathrm{~m}$ & $10 \%$ \\
\hline Caparide & $04 \mathrm{~h} 22 \mathrm{~m}$ & $02 \mathrm{~h} 37 \mathrm{~m}$ & $02 \mathrm{~h} 25 \mathrm{~m}$ & $8 \%$ \\
\hline Colares & $05 \mathrm{~h} 15 \mathrm{~m}$ & $03 \mathrm{~h} 01 \mathrm{~m}$ & $02 \mathrm{~h} 58 \mathrm{~m}$ & $2 \%$ \\
\hline Jamor & $05 \mathrm{~h} 19 \mathrm{~m}$ & $03 \mathrm{~h} 46 \mathrm{~m}$ & $03 \mathrm{~h} 28 \mathrm{~m}$ & $8 \%$ \\
\hline Laje & $05 \mathrm{~h} 55 \mathrm{~m}$ & $04 \mathrm{~h} 17 \mathrm{~m}$ & $03 \mathrm{~h} 36 \mathrm{~m}$ & $16 \%$ \\
\hline Vinhas & $03 \mathrm{~h} 41 \mathrm{~m}$ & $02 \mathrm{~h} 35 \mathrm{~m}$ & $02 \mathrm{~h} 31 \mathrm{~m}$ & $3 \%$ \\
\hline Alpriate & $02 \mathrm{~h} 56 \mathrm{~m}$ & $02 \mathrm{~h} 13 \mathrm{~m}$ & $02 \mathrm{~h} 03 \mathrm{~m}$ & $7 \%$ \\
\hline Fanhões & $03 \mathrm{~h} 04 \mathrm{~m}$ & $02 \mathrm{~h} 14 \mathrm{~m}$ & $02 \mathrm{~h} 11 \mathrm{~m}$ & $2 \%$ \\
\hline Loures & $06 \mathrm{~h} 41 \mathrm{~m}$ & $05 \mathrm{~h} 02 \mathrm{~m}$ & $04 \mathrm{~h} 57 \mathrm{~m}$ & $2 \%$ \\
\hline Póvoa & $04 \mathrm{~h} 57 \mathrm{~m}$ & $02 \mathrm{~h} 42 \mathrm{~m}$ & $02 \mathrm{~h} 32 \mathrm{~m}$ & $6 \%$ \\
\hline Trancão (SB) & $08 \mathrm{~h} 53 \mathrm{~m}$ & $05 \mathrm{~h} 19 \mathrm{~m}$ & $05 \mathrm{~h} 13 \mathrm{~m}$ & $2 \%$ \\
\hline Trancão (B) & $10 \mathrm{~h} 40 \mathrm{~m}$ & $14 \mathrm{~h} 08 \mathrm{~m}$ & $13 \mathrm{~h} 42 \mathrm{~m}$ & $3 \%$ \\
\hline
\end{tabular}

Para estimar os caudais de ponta de cheia das bacias estudadas recorreu-se ao Método Racional (Hipólito e Vaz, 2011; Almeida et al.coord., 2010). Dadas as limitações deste método procurou-se, essencialmente, avaliar os impactes que as alterações no uso do solo tiveram nos caudais de ponta. Esta avaliação foi feita com base no pressuposto seguinte: se as mesmas precipitações que desencadearam as cheias de 2008 (com os mesmos valores e a mesma distribuição espacial e temporal) tivessem ocorrido em 1990, quais seriam as diferenças nos caudais de ponta produzidos pelas diversas bacias? Os resultados deste exercício teórico estão no quadro X.

Quadro X - Simulação dos caudais de ponta de cheia (CP), calculados a partir das precipitações ocorridas em 2008, segundo o método Racional.

Table X-Simulation of the peak flood discharges (CP), according to the Rational Method, using 2008 precipitation event.

\begin{tabular}{ccccc}
\hline Bacias hidrográficas & $\begin{array}{c}\mathrm{CP}\left(\mathrm{m}^{3} / \mathrm{s}\right) \\
1990\end{array}$ & $\begin{array}{c}\mathrm{CP}\left(\mathrm{m}^{3} / \mathrm{s}\right) \\
2006\end{array}$ & $\begin{array}{c}\text { Aumento do CP } \\
\left(\mathrm{m}^{3} / \mathrm{s}\right)\end{array}$ & $\begin{array}{c}\text { Aumento do CP } \\
(\%)\end{array}$ \\
\hline Barcarena & 57,73 & 65,34 & 7,61 & 13 \\
Caparide & 9,36 & 10,61 & 1,26 & 13 \\
Colares & 17,20 & 17,78 & 0,58 & 3 \\
Jamor & 49,69 & 56,43 & 6,74 & 14 \\
Laje & 65,58 & 82,67 & 17,09 & 26 \\
Vinhas & 14,29 & 15,03 & 0,73 & 5 \\
Alpriate & 12,47 & 14,25 & 1,78 & 14 \\
Fanhões & 27,21 & 28,29 & 1,08 & 4 \\
Loures & 66,00 & 68,25 & 2,24 & 3 \\
Póvoa & 69,55 & 74,00 & 4,46 & $6 \%$ \\
Trancão (SB) & 50,19 & 51,67 & 1,48 & $3 \%$ \\
Trancão (B) & 132,10 & 138,63 & 6,53 & $5 \%$ \\
\hline
\end{tabular}


À semelhança do que acontece com os tempos de concentração, também nos caudais de ponta de cheia os maiores aumentos ocorrem nas bacias cujo processo de urbanização foi mais acentuado entre 1990 e 2006. O incremento foi particularmente significativo na bacia da Laje (26\%), mas estimaram-se também acréscimos importantes em Alpriate (14\%), Jamor (14\%), Barcarena (13\%) e Caparide (13\%).

\section{INTERAÇÃO DOS FACTORES NATURAIS E DA OCUPAÇÃO HUMANA}

Depois de analisados, separadamente, os factores naturais e antrópicos (uso do solo) das bacias hidrográficas estudadas foi possível estabelecer uma classificação final de susceptibilidade às cheias. Os resultados do ISfc (índice de susceptibilidade dos factores condicionantes) são apresentados no quadro XI e na figura 9.

\begin{tabular}{ccc}
\hline \multicolumn{3}{c}{ Factores Condicionantes } \\
\hline Posição & Bacia hidrográfica & ISfc \\
\hline $1^{\circ}$ & Póvoa & 3,02 \\
$2^{\text {o }}$ & Fanhões & 2,73 \\
$3^{\circ}$ & Alpriate & 2,68 \\
$4^{\circ}$ & Vinhas & 2,58 \\
$5^{\circ}$ & Trancão (SB) & 2,40 \\
$6^{\circ}$ & Jamor & 2,26 \\
$7^{\circ}$ & Barcarena & 2,23 \\
$8^{\circ}$ & Caparide & 2,21 \\
$9^{\circ}$ & Colares & 2,06 \\
$10^{\circ}$ & Loures & 2,05 \\
$11^{\circ}$ & Laje & 1,95 \\
\hline
\end{tabular}

Quadro XI - Susceptibilidade às cheias das bacias hidrográficas.

Table XI-Drainage basins susceptibility to flooding.

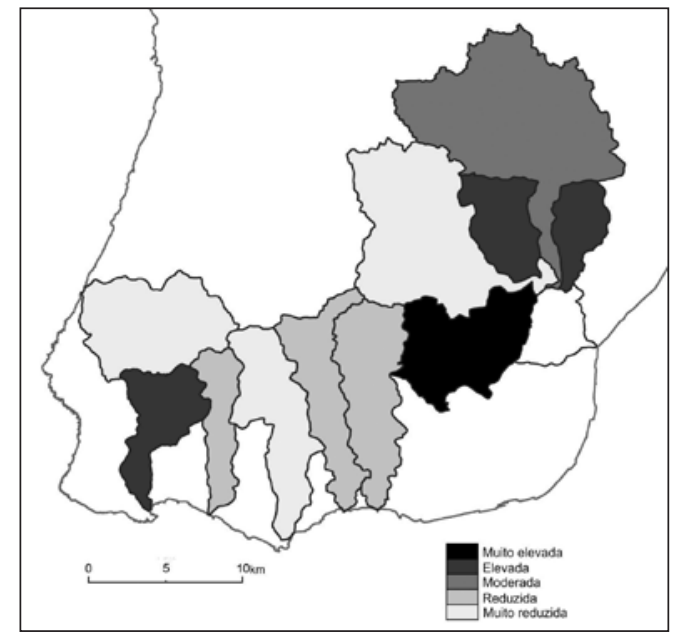

Fig. 9 - Susceptibilidade às cheias das bacias hidrográficas.

Fig. 9 - Drainage basins susceptibility to flooding.

A bacia mais susceptível às cheias é Póvoa, única com uma susceptibilidade muito elevada. De seguida surgem Fanhões, Alpriate e Vinhas com susceptibilidades elevadas, e Trancão (SB) com uma susceptibilidade moderada. Jamor, Barcarena e Caparide são pouco susceptíveis às cheias, enquanto em Colares, Loures e Laje a susceptibilidade é muito reduzida.

Nas cinco primeiras bacias, há quatro sub-bacias do rio Trancão (Póvoa, Fanhões, Alpriate e Trancão (SB)). A única excepção é Vinhas, que ocupa a quarta posição do ranking. Estes resultados mostram que a bacia do Trancão, e as suas sub-bacias, possuem características que agravam os efeitos das precipitações intensas. 
Outro aspecto relevante está relacionado com a bacia da ribeira da Laje. Em termos naturais, esta bacia é a menos susceptível às cheias rápidas; no entanto, o uso do solo torna-a muito menos permeável atendendo às suas condições naturais, o que a coloca na primeira posição quanto aos factores relativos ao uso do solo. Apesar disso, Laje é a menos susceptível às cheias no conjunto dos factores condicionantes, o que prova a importância decisiva das características naturais das bacias neste contexto.

Confirma-se que se as condições naturais condicionam a resposta das bacias aos episódios de precipitação, a intervenção humana tanto pode conduzir a um agravamento (como acontece na bacia da ribeira Póvoa) como a uma diminuição da susceptibilidade (como se observa nas bacias das ribeiras de Colares e de Loures).

\section{BALANÇO DA OCUPAÇÃO DAS ZAC NAAML NORTE}

Embora a análise tenha incidido sobre a totalidade das bacias hidrográficas, os elementos expostos às cheias encontram-se nos terrenos ribeirinhos inundáveis, ou seja, nas ZAC (DL n ${ }^{\circ}$ 166/2008 e Ramos et al., 2010). Em termos genéricos, na AML Norte, são as bacias mais urbanizadas as que têm mais construções em leito de cheia (quadro VII e fig. 10). Contudo, há algumas excepções, como acontece na bacia das Vinhas, que tem quase a totalidade das suas ZAC ocupadas por edifícios (Baixa de Cascais) apesar do seu cariz florestal, e na bacia de Caparide, que, apesar da sua feição urbana $(45,8 \%)$, tem menos de $10 \%$ das suas ZAC ocupadas por áreas edificadas.

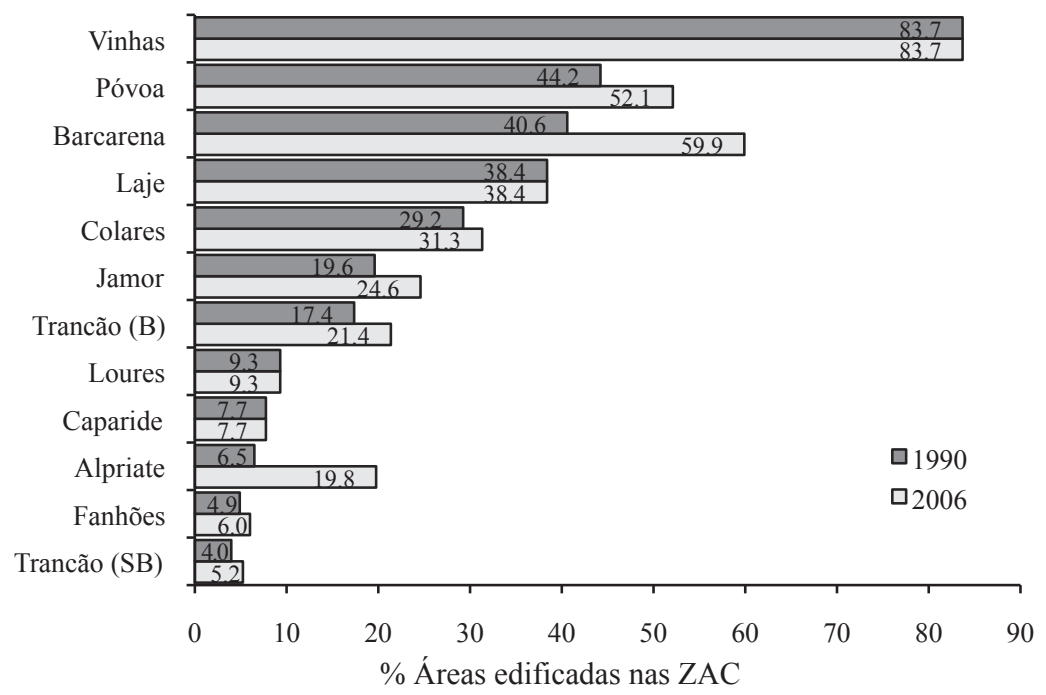

Fig. 10 - Evolução das áreas edificadas nas ZAC, entre 1990 e 2006.

Fig. 10 - Built areas evolution on the flood-prone zone, between 1990 and 2006. 
Nem todas as bacias registaram um aumento da área edificada entre $1990 \mathrm{e}$ 2006. É o caso de Caparide, Laje, Vinhas e Loures. Em Colares, Fanhões e Trancão (SB), o aumento não foi muito significativo; pelo contrário, em Barcarena (19\%), Alpriate (13\%), Póvoa, (8\%) e Jamor (5\%) ocorreu um crescimento expressivo (fig.10).

As bacias que mais se destacam, quanto à evolução da área construída, são: 1) Vinhas, que tem mais de $80 \%$ das suas $Z A C$ com construções, uma vez que o troço terminal da ribeira foi canalizado subterraneamente e a Baixa de Cascais foi edificada sobre ele; 2) Póvoa e Barcarena, que, em 2006, já tinham mais de metade das suas ZAC ocupadas por áreas edificadas, tendo o crescimento continuado a aumentar; 3) Alpriate, que teve um forte crescimento em 16 anos, triplicando a área edificada. Estes resultados mostram que a legislação existente, que condiciona a construção em leito de cheia, não é cumprida. Nas últimas décadas, o abandono da agricultura criou terrenos expectantes para a urbanização potenciando uma elevada pressão sobre estes terrenos, no sentido da substituição do uso rústico pelo urbano.

\section{CONCLUSÃO}

Na avaliação da susceptibilidade às cheias, das 12 bacias hidrográficas da AML Norte, foi utilizada uma metodologia que se considerou adequada para a escala de análise utilizada, pois permite a comparação entre bacias através da conjugação de um número apreciável de indicadores, capaz de dotar a análise de grande robustez. Como qualquer método, este possui algumas limitações, nomeadamente a atribuição dos scores aos factores condicionantes cujo valor pode ser discutível. Para além disso, os resultados não podem ser completamente validados, dado que os dados hidrométricos existentes são insuficientes. Contudo, este método permite detetar em cada bacia quais os fatores que as tornam particularmente sensíveis às cheias, podendo ajudar na escolha de tipos de intervenção que ajudem a minimizar as consequências nefastas deste fenómeno.

A avaliação efetuada mostra que os factores de predisposição (naturais) são particularmente gravosos (susceptibilidade elevada a muito elevada) nas sub-bacias do Rio Trancão (Fanhões, Trancão/sub-bacia, Póvoa/Odivelas e Alpriate), cujo escoamento converge na várzea de Loures, bem como na da ribeira das Vinhas, que desagua em Cascais, enquanto os factores variáveis (uso do solo) são particularmente gravosos nas bacias da ribeira da Laje e da Póvoa/Odivelas. A conjugação dos factores agravantes das cheias (naturais e da ocupação humana) mostra que a bacia da ribeira da Póvoa é, de todas, a mais susceptível a este fenómeno, constituindo um verdadeiro desafio na mitigação das cheias na AML Norte.

A crescente expansão das áreas urbanizadas, essencialmente em detrimento dos terrenos agrícolas, implica a progressiva impermeabilização dos terrenos com o consequente aumento da magnitude das cheias, ou seja, da sua perigosidade. No período 
analisado (entre 1990 e 2006), as bacias que drenam a chamada Costa do Sol foram as mais afetadas por este fenómeno, registando os maiores aumentos dos caudais de ponta (Laje, Jamor, Barcarena e Caparide).

Ao nível dos leitos de cheia (ZAC) também se observa a tendência de alastramento das áreas construídas apesar da legislação existente. Em consequência, à excepção de quatro bacias, a exposição às cheias cresceu, potenciando assim o aumento do risco de cheia na AML. São de salientar os casos das bacias das ribeiras de Barcarena, em que a área construída nos leitos de cheia aumentou de $41 \%$ para $60 \%$ e da ribeira de Alpriate (de $7 \%$ para $20 \%$ ).

A densificação da construção nas ZAC implica, à posteriori, a aplicação de medidas de mitigação estruturais, muito onerosas para os cofres públicos, tais como a rectilinearização dos canais, aprofundamento dos leitos e diques de protecção nas margens. É urgente a passagem do paradigma de "consumo do território" que exige medidas estruturais para remediar a situação, para um novo paradigma, o do Princípio da Precaução: «manter as pessoas e bens afastados das cheias», exigência intrínseca ao (re)ordenamento do território.

\section{BIBLIOGRAFIA}

Almeida A B, Oliveira R P, França P, Rodrigues D, Silva D F (2010) Estudo de avaliação do risco de aluviões na Ilha da Madeira. Relatório Síntese (versão 0.99d). Instituto Superior Técnico, Universidade da Madeira e Laboratório Regional de Engenharia Civil, IP-RAM.

Borges B, Duarte A, Pancada R, Pedro P, Ramos C (2005) Cheias rápidas em áreas urbanas e sua percepção: o caso da bacia da $\mathrm{R}^{\mathrm{a}}$ de Odivelas. Actas do X Colóquio Ibérico de Geografia, Évora, CD-ROM: 15p.

Carvalho R (1998) Hidrologia e Recursos Hidricos. In Estúdios Cor, S.A. (ed) O ciclo natural da água. Lisboa, 1.

Correia F N (1983) Proposta de um método para a determinação de caudais de cheia em pequenas bacias naturais e urbanas. In Seminário Contribuição para o estudo de métodos de cálculo de drenagem de águas pluviais em zonas urbanas, Laboratório Nacional de Engenharia Civil, Lisboa: 249-270.

DL no 166/2008 (2008) Nova Lei da Reserva Ecológica Nacional. Decreto-Lei $n .^{\circ} 166 / 2008$, Diário da República, 1. ${ }^{\mathrm{a}}$ série — N. ${ }^{\circ} 162-22$ de Agosto de 2008, Ministério do Ambiente, do Ordenamento do Território e do Desenvolvimento Regional.
Hipólito J, Vaz A (2011) Hidrologia e recursos hidricos. Colecção Ensino da Ciência e da Tecnologia, IST Press, Lisboa, 41.

Julião R P (coord.) (2009) Guia metodológico para a produção de cartografia municipal de risco e para a criação de Sistemas de Informação Geográfica de base municipal. ANPC, DGOTDU, IGP, Lisboa.

Lavrador-Silva A (2002) Avaliação das paisagens da bacia hidrográfica da ribeira de Colares: estudo geográfico e de percepção ambiental. Dissertação de mestrado em Geografia Física e Ambiente, Faculdade de Letras, Universidade de Lisboa, Lisboa.

Leal M (2011) As cheias rápidas em bacias hidrográficas da AML Norte: factores condicionantes e desencadeantes. Dissertação de mestrado em Geografia Física e Ordenamento do Território, Instituto de Geografia e Ordenamento do Território, Universidade de Lisboa, Lisboa.

Lencastre A, Franco F M (2006) Lições de hidrologia. Fundação da Faculdade de Ciências e Tecnologia da Universidade Nova de Lisboa, Lisboa.

Leopold L (1968) Hydrology for urban land planning - a guidebook on the hydrologic effects 
of urban land use. Geological Survey Circular 554, United States Department of the Interior.

Lima J, Lima I (2010) Conceitos básicos de hidrologia. In Lima J (coord.) Hidrologia urbana conceitos básicos. Universidade de Coimbra e Entidade Reguladora dos Serviços de Água e Resíduos, Lisboa: 143-175.

Miller S, Kepner W, Mehaffey M, Hernandez M, Miller R, Goodrich D, Devonald K, Heggem D, Miller P (2002) Integrating landscape assessment and hydrologic modeling for land cover change analysis. Journal of the American Water Resources Association, 38(4): 915 $-929$.

NOAA (2010) Flash flood early warning system reference guide. COMET Program, University Corporation for Atmospheric Research (UCAR)

Patton P (1988) Drainage basin morphometry and floods. In Baker V, Kochel R C, Patton P (eds.) Flood geomorphology. John Wiley and Sons, New York: 51-64.

Ramos C (2009) Dinâmica fluvial e ordenamento do território. Centro de Estudos Geográficos, SLIF 6, Universidade de Lisboa, Lisboa.

Ramos C (1994) Condições geomorfológicas e climáticas das cheias da Ribeira de Tera e do Rio Maior (bacia hidrográfica do Tejo). Dissertação de doutoramento em Geografia Física, Faculdade de Letras, Universidade de Lisboa, Lisboa.

Ramos C, Zêzere J L, Reis E, Mendonça J L (2010) Reserva ecológica nacional da Área Metropolitana de Lisboa. Quadro de referência regional. Comissão de Coordenação e Desen- volvimento Regional de Lisboa e Vale do Tejo, Lisboa. [Acedido em 26 de Março de 2012] http://www.ccdr-lvt.pt/content/index. php?action=detailfo\&rec $=1913 \& \mathrm{t}=$ Areas-de-REN---Quadro-de-Referencia-Regional.

Reis E (2006) As bacias hidrográficas das Ribeiras da Serra de Grândola - dinâmica hidrológica e factores condicionantes. Dissertação de doutoramento em Geografia (Geografia Física), Faculdade de Letras, Universidade de Lisboa, Lisboa.

Reis E (1996) Aplicação dos Sistemas de Informação Geográfica na análise morfológica de bacias hidrográficas. Dissertação de mestrado em Hidráulica e Recursos Hídricos, Instituto Superior Técnico, Universidade Técnica de Lisboa, Lisboa.

Saraiva M G, Correia F N, Carmo V (1998) Avaliação ex-post de medidas não-estruturais de defesa contra cheias na bacia hidrográfica da Ribeira da Lage. $4^{\circ}$ Congresso da Água, Lisboa.

Smith K, Ward R (1998) Floods. Physical processes and human impacts. John Wiley \& Sons, Chicester.

Soeters R, Van Westen C J (1996) Slope instability recognition, analysis and zonation. In Turner A K, Schuster R L (Eds.) Landslides, investigation and mitigation. Transportation Research Board, National Research Council, Special Report 247. National Academy Press, Washington D.C.: 129-177.

Temez J (1978) Calculo hidrometeorologico de caudales máximos en pequeñas cuencas naturales. MOPU, Dirección General de Carreteras, Madrid, 12 .

Os autores deste texto escrevem segundo o novo acordo ortográfico.

i Alguns destes indicadores são conhecidos na literatura científica como "índices" (exemplo: Índice de Gravelius).

ii A bacia do Trancão não faz parte da avaliação da susceptibilidade às cheias porque a área das suas sub-bacias (Póvoa, Loures, Fanhões, Alpriate e sub-bacia do Trancão) representa quase 95\% da sua superfície.

iii Os valores de permeabilidade das formações geológicas que compõem as bacias estudadas podem ser consultados em Leal (2011). 